Beech, F. W., Carr, J. G. \& Conner, R. C. (1955). J. gen. Microbiol. 13, 408-410

\title{
A Multipoint Inoculator for Plating Bacteria or Yeasts
}

\author{
By F. W. BEECH AND J. G. CARR \\ Research Station, Long Ashton, Bristol \\ AND R. C. CODNER \\ Antibiotics Research Station, Clevedon, Somerset
}

SUMMARY : A multipoint inoculator has been designed for inoculating agar plates with a maximum of twenty-four strains of bacteria or yeasts simultaneously.

In a previous paper (Beech \& Carr, 1955) describing the effect of inhibitory compounds on bacteria and yeasts it was found necessary to make approximately 15,000 separate inoculations. This was time-consuming, and since each plate had to be opened twenty-four times the chances of aerial contamination were considerable. The same problem arises when determining the utilization of sugars, etc., by yeasts, with the auxanographic plate method. These difficulties may be overcome by the simultaneous inoculation of the plate with the required number of organisms.

Earlier references to such methods have been a multiple-point needle (Garrett, 1946) for inoculating an agar plate with plaques of mould colonies and a replica plating method using circles of velveteen (Lederberg \& Lederberg, 1952). Garrett's instrument was not ideal for bacteria and yeasts. In the second method each velveteen circle can only be used for approximately five plates since the inoculum size diminishes with each transfer. Further, this method requires plates inoculated in a pre-arranged pattern as a source of the test organisms. It was considered that a modification of Garrett's instrument with the use of liquid inocula would be more suitable for bacteria and yeasts.

The complete apparatus, illustrated on Pl. 1, figs. 1-3, consists of an inoculum tube holder, a multipoint inoculator and a Petri dish holder. Stainless steel, FMB grade, was used for all metal parts, although other non-corrodible metals could be substituted.

Inoculum tube holder. This is a circular metal base plate drilled with twentyfour equally spaced holes, each capable of holding a $9 \times 50 \mathrm{~mm}$. Durham tube. On top of this is a block of smaller diameter consisting of two circular metal disks interleaved with heat-resisting rubber, all drilled in the same pattern as the base plate and held in position with screws; two vertical guides are also attached to the base plate. The holes in the rubber sheet are slightly smaller than those in the metal disks and serve to hold the Durham tubes tightly in position.

Inoculator. This consists of twenty-four vertical metal rods, $\frac{1}{8}$ in. diameter with truncated ends which prevent the inocula dripping during transfer. The ods are tapped into the inner basal surface of an inverted metal cup and are 
positioned to correspond with the centres of the twenty-four holes. The cup is grooved externally to engage with the vertical guides of the inoculum tube holder, and is surmounted by a heat-resistant, insulated handle.

Petri dish holder. This, like the inoculum tube holder, has a base plate and two vertical guides, but the base is recessed slightly to accommodate a Petri dish.

\section{Inoculation procedure}

Durham tubes are inserted in the tube holder and covered with aluminium caps (Oxo Ltd., Medical Dept., Thames House, London, E.C. 4). The complete holder and multipoint inoculator are each wrapped in brown paper and sterilized by autoclaving at $15 \mathrm{lb}$./sq.in. for $15 \mathrm{~min}$. A covered Petri dish containing $20 \mathrm{ml}$. sterile nutrient agar is placed on the Petri dish holder. The tube holder is unwrapped and the caps covered with an inverted sterile glass dish: each cap is discarded in turn after the addition of $1 \mathrm{ml}$. inoculum to the corresponding tube. The inoculator is unwrapped, the glass dish removed and held in one hand, while the inoculator is pushed down the guides into the tubes of inoculum. The inoculator is then withdrawn and the tubes re-covered. The lid of the Petri dish is removed with one hand, and the inoculator pushed down the guides of the inoculum tube holder. Set screws are fitted into the top surfaces of the guides on the Petri dish holder and are adjusted beforehand so that when they bear on the base of the handle, the inoculating rods just touch the agar surface. The inoculator is removed and the Petri dish cover replaced. A fresh plate is then placed on the holder and the cycle repeated. In this way a plate may be inoculated simultaneously with twenty-four organisms in $30 \mathrm{sec}$. compared with $8 \mathrm{~min}$. required for inoculating them singly with a wire loop (Pl. 2, figs. 4, 5). Since the inoculator is bilaterally symmetrical it is advisable to mark one of the grooves and one guide on each holder with cellulose paint. A mark should also be made on the outside of the Petri dish.

To prevent the drops of inoculum from coalescing on the agar plate it is essential to dry the surface of the medium before inoculation, to leave the inoculated plates on the work bench until the drops have dried and, most important, not to add surface-active agents, e.g. Tween-80, to the medium.

Size of spot. To estimate the volume of inoculum deposited by each rod, $1 \mathrm{ml} .20 \% \mathrm{NaCl}$ was added to each inoculum tube and the rod holder pressed home. The drops of $\mathrm{NaCl}$ solution were transferred to a dried plate of $2 \%$ washed agar using the procedure outlined previously. Twenty-four circles of agar, each with a drop in the centre, were cut out with a cork borer and placed in individual $100 \mathrm{ml}$. conical flasks. Two other plates were each inoculated six times with the same $\mathrm{NaCl}$ solution for comparison but using a conventional $4 \mathrm{~mm}$. wire loop. Comparable circles of agar, without $\mathrm{NaCl}$, were also removed as controls. $10 \mathrm{ml} .0 \cdot 9 \mathrm{~N}-\mathrm{HNO}_{3}$ was added to each flask, heated to dissolve the agar, cooled and the amount of chloride present estimated by an adaptation of Volhard's volumetric method for chlorides (Vogel, 1939). From this data the volumes of the chloride spots could be calculated. 
The average volume deposited by each rod was $0.01 \mathrm{ml}$. with a variation of $\pm 25 \%$. By comparison spots from the $4 \mathrm{~mm}$. platinum loop were $0.005 \mathrm{ml}$. with a variation of $\pm \mathbf{2 5} \%$. Both methods showed some discrepancies; thus the size of the spot deposited by the rods could be varied by the speed with which they were withdrawn from the inoculum holder. The wire loop suffered from the same defect, and in addition the volume deposited was increased by pressing the loop more heavily on to the agar.

On the basis of these observations the multipoint inoculator, at its present stage of development, is no less subject to variation than the wire loop but it has the advantage of greater speed in operation. It is suitable, therefore, for rapid surveys of a semi-quantitative nature.

We wish to thank Miss M. E. Kieser, B.Sc., A.R.I.C., for adapting the chloride method, Mr D. J. Sissons for the chemical determinations and Mr G. H. Jones, A.R.P.S., for taking the photographs illustrating this article.

\section{REFERENCES}

BeEch, F. W. \& CarR, J. G. (1955). A survey of inhibitory compounds for the separation of yeasts and bacteria in apple juices and ciders. J. gen. Microbiol. 12,85 .

Garrett, S. G. (1946). A multiple-point inoculating needle for agar plates. Trans. Brit. mycol. Soc. 29, 171.

Lederberg, J. \& Lederberg, E. M. (1952). Replica plating and indirect selection of bacterial mutants. J. Bact. 63, 399 .

Vogel, A. I. (1939). Quantitative Inorganic Analysis, 1st ed. London: Longmans Green and Co.

\section{EXPLANATION OF PLATES}

Plate 1

Fig. 1. Inoculum tube holder ready for use.

Fig. 2. Oblique view of the inoculator.

Fig. 3. Petri dish holder with uninoculated plate in position.

Plate 2

Fig. 4. Petri dish showing 23 colonies of three different species of lactic acid bacteria inoculated simultaneously.

Fig. 5. As Fig. 1, showing 24 colonies of three different species of yeasts inoculated simultaneously. 
Journal of General Microbiology, Vol. 13, No. 3

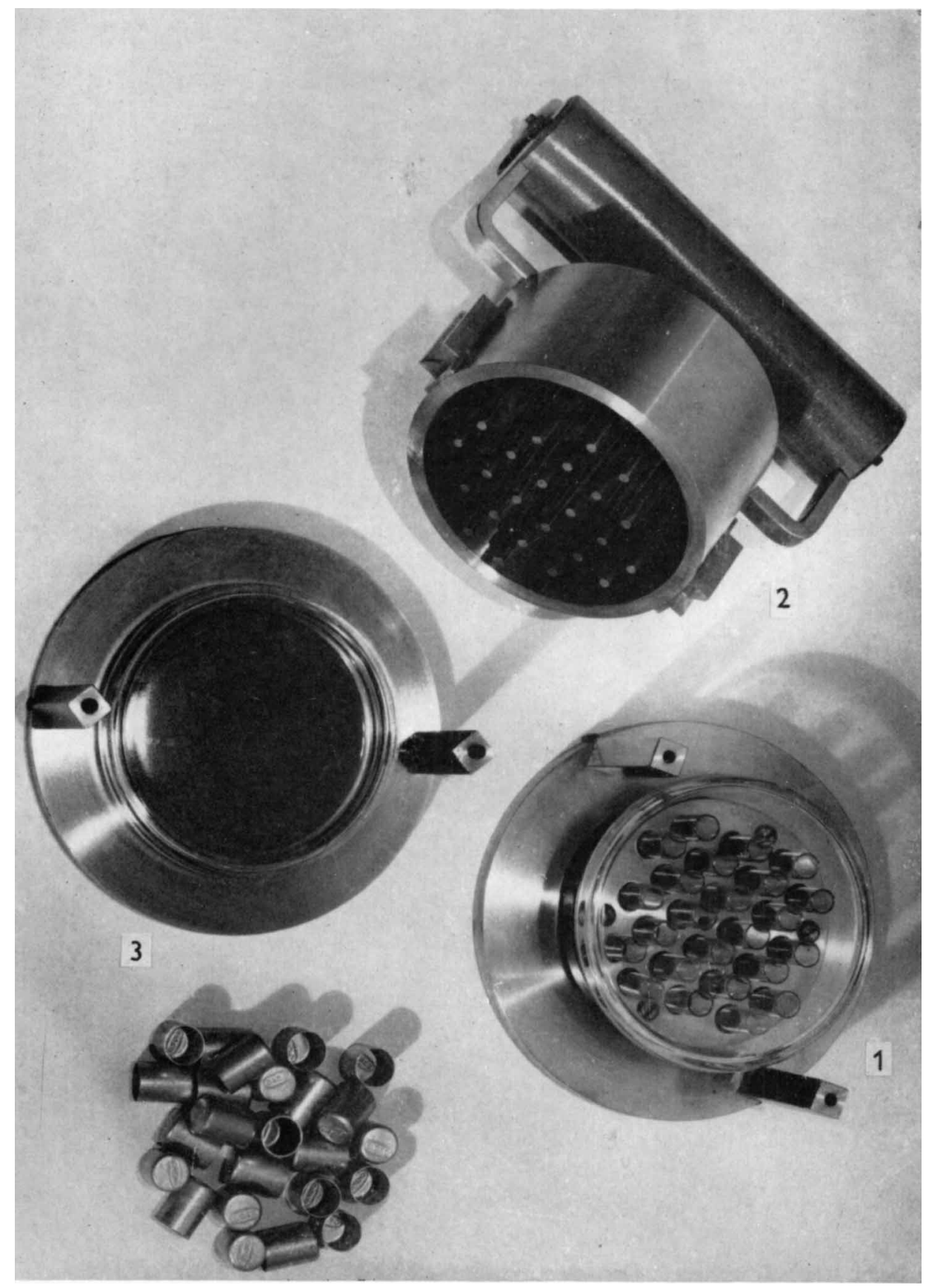

F. W. Befch, J. G. Carr \& R. C. Codner--A mutipoint inocllator. Plate 1 
Journal of General Microbiology, Vol. 13, No. 3

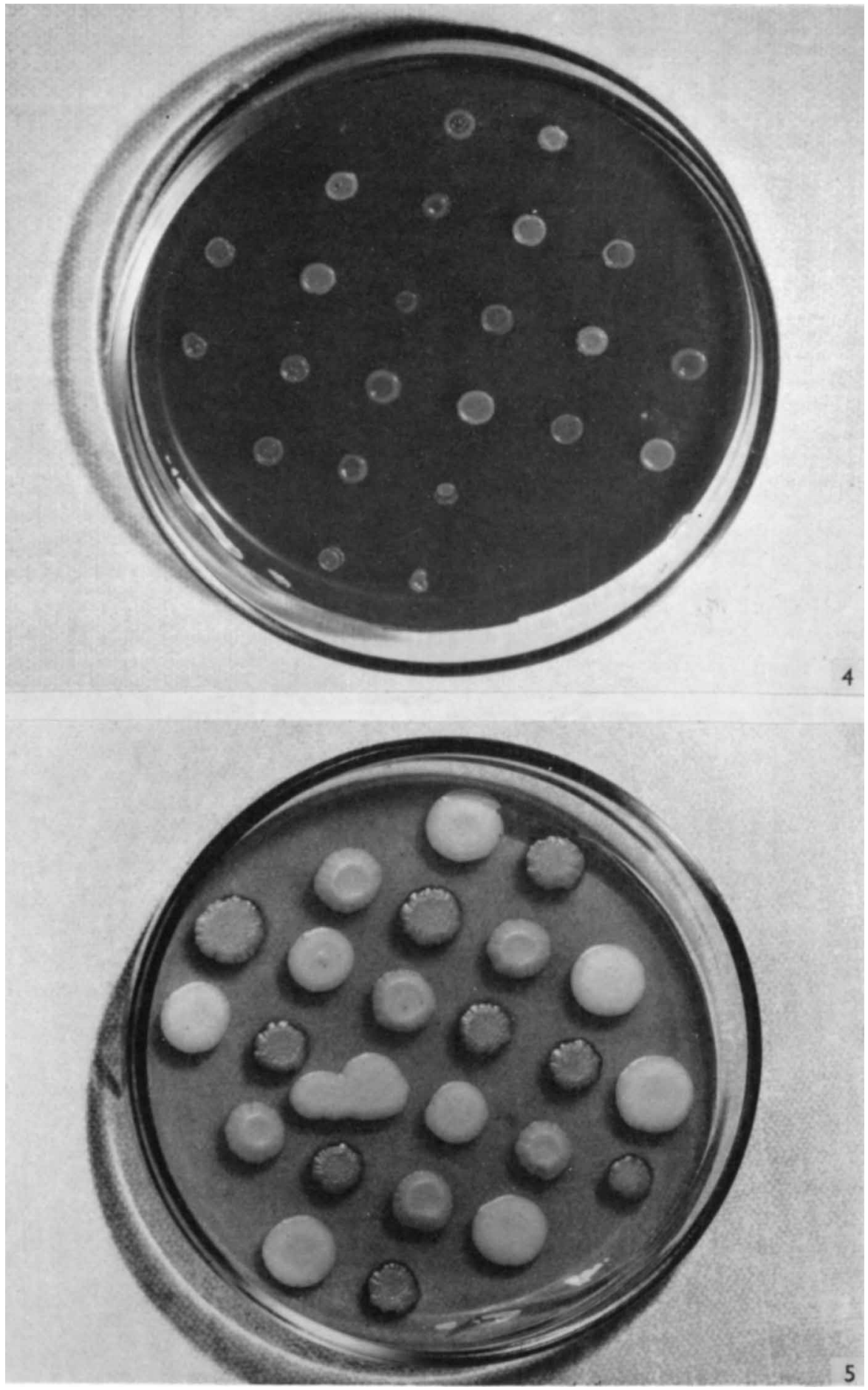

F. W. Befch, J. G. Carr \& R. C. Codner-A multipoint inoculator. Plate 2 